\title{
The Effects of an Experimental Green Tea Extract Gel on the Surface Roughness of Bleached Teeth with Carbamide Peroxide Gels
}

\author{
CORINA VOINA ${ }^{1}$, ADRIANA MURESAN ${ }^{2}$, ADA DELEAN ${ }^{1}$, \\ AMALIA IONELA MOLDOVAN ${ }^{3}$, VIOLETA POPESCU ${ }^{3}$, DOINA PRODAN ${ }^{4}$, \\ IOAN PETEAN ${ }^{5 *}$, ANDRADA VOINA-TONEA ${ }^{6}$, MADALINA VALEANU ${ }^{7}$
}

${ }^{1}$ University of Medicine and Pharmacy "Iuliu Hatieganu", Faculty of Dental Medicine, Department of Odontology and Oral Pathology, 33 Motilor Str., 400001, Cluj-Napoca, Romania

${ }^{2}$ University of Medicine and Pharmacy "Iuliu Hatieganu", Faculty of Medicine, Department of Functional Sciences, 3 Clinicilor Str., 400006, Cluj-Napoca, Romania

${ }^{3}$ Technical University of Cluj-Napoca, Physics and Chemistry Department, 28 Memorandumului Str., Cluj-Napoca 400114, Romania

${ }^{4}$ Babes-Bolyai University, Department of Polymer Composites, Institute of Chemistry Raluca Ripan, 30 Fantanele Str., 400294 Cluj-Napoca, Romania

${ }^{5}$ Babes Bolyai University, Faculty of Chemistry and Chemical Engineering, 11 Arany Janos Str., 400084, Cluj - Napoca, Romania

${ }^{6}$ University of Medicine and Pharmacy "Iuliu Hatieganu", Department of Dental Matherials, Faculty of Dental Medicine, 15 Babes Victor Str., 400012, Cluj-Napoca, Romania

${ }^{7}$ University of Medicine and Pharmacy "Iuliu Hatieganu", Faculty of Medicine, Department of Medical Informatics and Biostatistics, 6 Pasteur Louis Str., 400349, Cluj-Napoca, Romania

Abstract: Esthetics of the enamel surface is an important factor for a good oral health care. The mastication process could damage the enamel surface by hydroxyapatite layer alteration via local demineralization and micro scratches. We developed an experimental green tea extract gel for enamel restoring treatment. Microstructure features were investigated by SEM microscopy and the surface details were revealed by AFM. The surface roughness and hydroxyapatite grains size and shape were the parameters followed into the investigation. The results show that the best restoring is obtained by the experimental gel leading to surface parameters similar to the healthy enamel better than the values obtained with opalescence carbamide gel.

Keywords: re-mineralization, tooth enamel, surface roughness

\section{Introduction}

A good appearance of teeth is a great concern for the patients, who seek aesthetic treatments in order to eliminate tooth discolorations [1]. Among the treatment methods, tooth whitening has attracted the interest of patients and, also dentists, because it is a non-invasive technique and relatively easy to perform [2].

The most used bleaching products contain carbamide peroxide and the concentrations most commonly used and indicated to patients by the dental practitioners are $10 \%$ and $15 \%$, respectively. It is known that exposed to buccal fluids, the carbamide peroxide gel breaks down into water, urea and oxygen. Also, the amount of oxygen released from the $10 \%$ carbamide peroxide gel is equivalent to that of $3 \%$ hydrogen peroxide [3].

The mechanism of action of teeth whitening gels is based on oxygen free radicals, released by decomposition of carbamide peroxide or hydrogen peroxide [4]. These free radicals responsible for the whitening effect, through oxidation, also produce physical and chemical changes [5] of the dental structure, reducing the proportions of important enamel components, such as: calcium, fluorides and phosphates [6-8].

*email: petean.ioan@gmail.com 
Green tea is a leading drink in the Far East for thousands of years before it became a popular hot and cold drink worldwide. Many studies have suggested that the consumption of green tea is associated with the reduction of the risk of several pathologies and an increasing number of evidences mentioning a beneficial role of green tea in oral health [9].

Green tea contains polyphenols such as: epicatechin (EC), epigalocatechin (EGC), epicatechingalate (ECG) and epigalocatechingalate (EGCG). Epigalocatechin-3-gallate is the main chemo-active constituent of green tea. Green tea leaves also contain caffeine, theanine, micricetin, quercetin and kaempferol, all of which are part of the alkaloid group. The varied chemical composition of green tea has been explored in different biomedical fields, with an accent on the antioxidant, anticancer and anti-inflammatory potential of EGCG [10-13]. The EGCG structure includes a benzenediol ring attached to a tetrahydropyran fraction, a pyrogalol ring and a galloyl group (with the pyrogalol ring) [14, 15]. The structural characteristics of catechins contained in green tea, which contribute significantly to their antioxidant action, are the presence or absence of the gallium part and the number and positions of the hydroxyl groups on the rings. These chemical fractions present the ability to interact chemically by hydrogen bonding or by electron and hydrogen transfer processes in their antioxidant activities. In fact, the antioxidant mechanism involves hydrogen atom transfer or single electron transfer reactions, or both. It is also believed that tea catechins exhibit antioxidant activity, which eliminates the lipid and peroxyl alkoxyl radicals, acting as antioxidants that break the molecular chain [16].The present study aims to evaluate the effect of the experimental extract based on green tea on the surface changes of the tooth enamel bleached with carbamide peroxide gels.

\section{Materials and methods}

Enamel surfaces used in this article are collected from 28 healthy molars which were extracted for orthodontic purposes. They were taken into study and randomly divided into four experimental groups, as follows: GCN group, which served as control group, GCC group, stained control group and GO groups and GE, which were designated experimental groups.

Treatment of the enamel surface was performed by two gels: a commercial one $-16 \%$ carbamide peroxide (PC) bleaching gel (Opalescence, Ultradent Products, South Jordan, UT, USA) and the experimental green tea extract and carbamide peroxide bleaching gel

The 28 teeth were mounted in self-curing acrylate prisms (Duracryl Plus, Spofadentallnc, Jičín, Czech Republic) up to the level of the enamel-dentin junction, keeping the entire coronary portion free.

\section{Staining protocol}

The experimental groups GCC, GO and GE were subjected to a staining process, the molars being immersed in coffee solution $8 \mathrm{~h} /$ day, for 3 consecutive days. The coffee solution was prepared in the Saeco Pico Baristo machine in espresso mode, using 5 grams of Lavazza coffee (Luigi Lavazza SpA, Turin, Italy) in $100 \mathrm{~mL}$ of water. Freshly prepared coffee solution was used at each session. Between the staining sessions, the teeth were kept immersed in artificial saliva at $37^{\circ} \mathrm{C}$.

\section{Bleaching protocol}

The whitening protocol aimed to simulate a home- used bleaching treatment, using individualized trays. Thus, $16 \%$ carbamide peroxide bleaching gel (Opalescence, Ultradent Products, USA) was applied to the GO group $6 \mathrm{~h} /$ day for 7 consecutive days. The GE study group was bleached with the experimental gel $6 \mathrm{~h} /$ day for 7 consecutive days. At the end of each bleaching step, teeth were rinsed for $60 \mathrm{~s}$ in water and then stored in artificial saliva at $37^{\circ} \mathrm{C}$.

\section{Preparation of the experimental extract}

The green tea based experimental extract was prepared at the "RalucaRipan" Chemistry Institute of Babes-Bolyai University, Cluj-Napoca as follows: $20.0 \mathrm{~g}$ of green tea leaves were added to $200 \mathrm{~mL}$ of 
boiled distilled water (R. Twining and Company Limited, London, UK). The extract solution was left to infuse for $10 \mathrm{~min}$. The obtained product was filtered to remove possible impurities and was stored in sterile containers at $4^{0} \mathrm{C}$ for later use. To obtain the experimental bleaching gel, the extract solution was used, to which carbamide peroxide, polyethylene glycol and silicon dioxide were added according to the formula: $100 \mathrm{~g}$ experimental bleaching gel contains: $22.2 \mathrm{~g}$ polyethylene glycol, $7.7 \mathrm{~g}$ silicon dioxide, $16 \mathrm{~g}$ carbamide peroxide and $54,1 \mathrm{~g}$ green tea extract.

At the end of the experiment, slices from the vestibular portion of the molars from each study group (GCN, GCC, GO and GE) were taken in order to analyze the enamel aspect by scanning electron microscopy and atomic force microscopy.

All experimental groups were evaluated by scanning electron microscopy (SEM) to highlight the modification of the tooth surface as a result of the staining treatment and then bleaching. For comparison, we used as a control the group of, molars (GCN) not subjected to staining and bleaching processes. The samples were examined using an Inspect-S microscope (FEI Company USA). Several imaging units were used, and the recordings were made on the surface of the tooth enamel.

The atomic force microscopy (AFM) was performed on a JEOL JSPM 4210 Scanning Probe Microscope, Japan. The topographic images were recorded in tapping mode using NSC 15 cantilevers produced by Micromesh Co. Bulgaria (resonant frequency $325 \mathrm{kHz}$ and force constant $40 \mathrm{~N} / \mathrm{m}$ ). Enamel microstructure was scanned at an area of $5 \mu \mathrm{m} \times 5 \mu \mathrm{m}$ at a scan rate of about $1 \mathrm{~Hz}$ and the nanostructure was scanned at area of $1 \mu \mathrm{m} \times 1 \mu \mathrm{m}$ at a rate of $1.5-2 \mathrm{~Hz}$. The AFM topographic images were processed using WinSPM 2.0 Processing soft powered by JEOL for the AFM microscopes.

\section{Results and discussions}

The overall condition of the enamel is very well observed in the SEM images for the control group (GCN) made up of molars not subjected to any experimental treatment. Figure 1 shows the regular architecture of hydroxyapatite prisms, with only a few lesions related to tooth wear due to mastication.

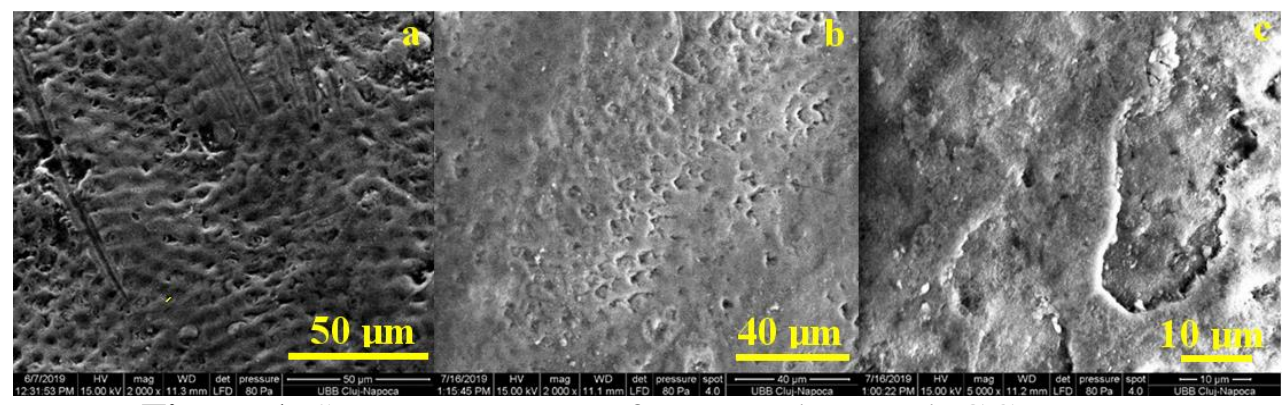

Figure 1. SEM appearance of untreated enamel, GCN group

In the stained control group (GCC), as it showed in Figure 2, we observe the deposits of the staining substance on the surface of the enamel level, somehow covering the tooth wear injuries.

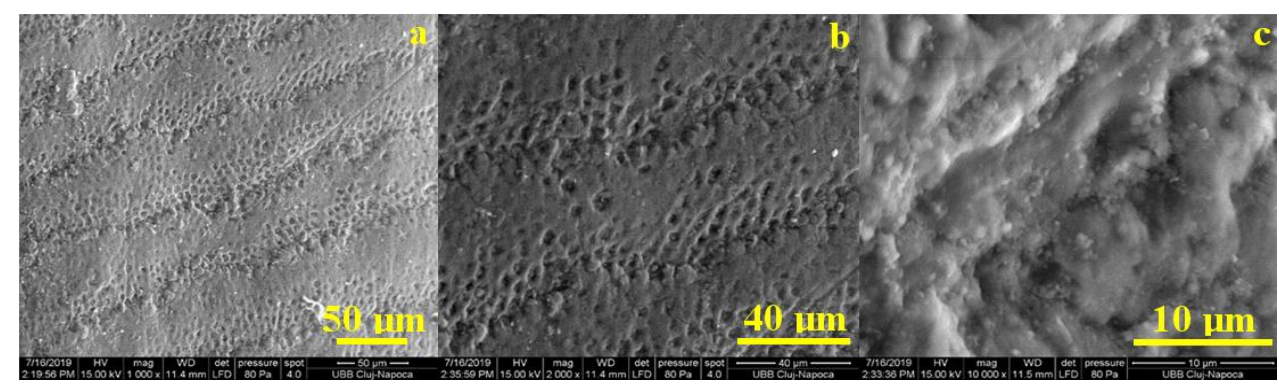

Figure 2. SEM appearance of the stained enamel, GCC group 
In the SEM analysis after staining with coffee solution and bleaching with Opalescence gel, it is observed the change in the appearance of the surface of the tooth enamel, which is smooth, with small irregularities. However, comparing the appearance of the dental surfaces in this group with those of the control group, we observe that the architecture has changed. Enamel architecture is no longer similar to that of the untreated control group. The whitening gel smoothed the surface of the enamel somewhat, removing both the deposits from the chromophore molecules and the traces of wear (Figure $3)$.

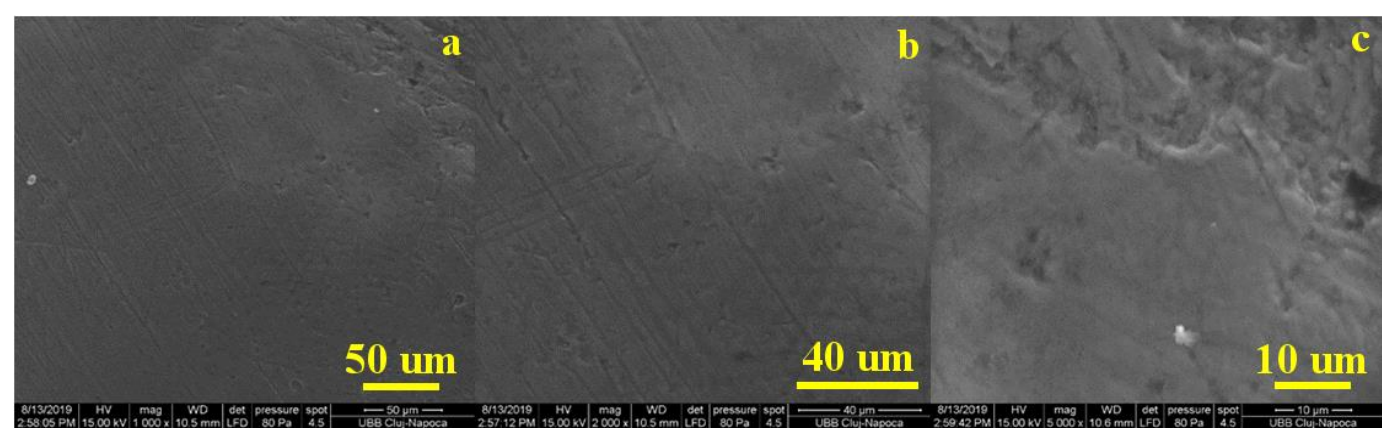

Figure 3. SEM appearance of the enamel bleached with Opalescence gel

In the case of teeth whitened with experimental gel, the following aspect was observed at SEM: the chromophore molecules were removed from the enamel surface, which appeared somewhat smooth. However, the dental surfaces show no similarities to the experimental group bleached with Opalescence gel, which appears to be covered with a protective film, as it is showed in Figure 4.

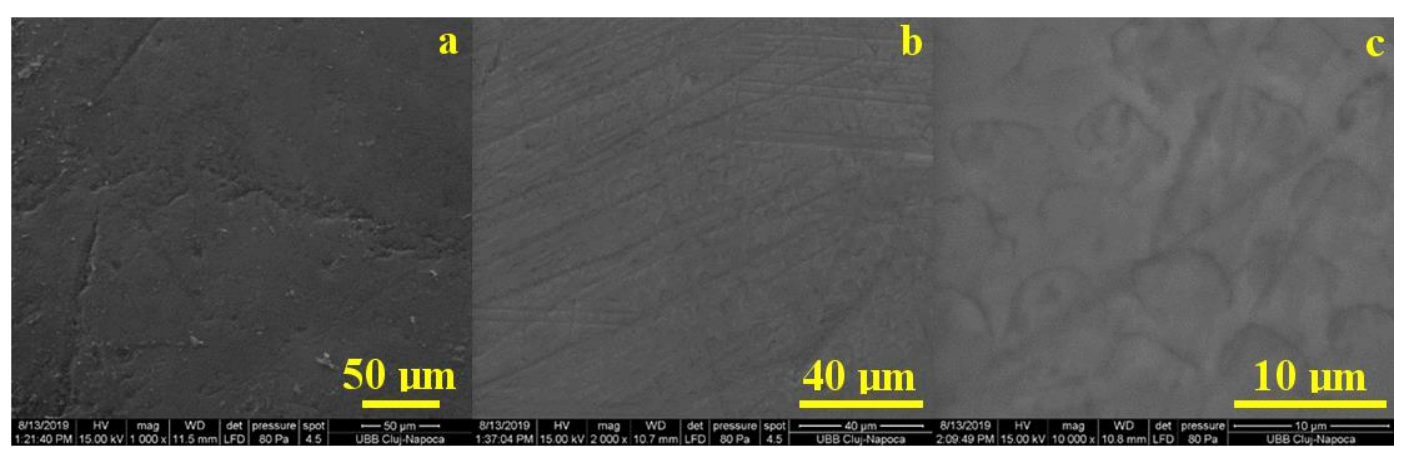

Figure 4. SEM appearance of the enamel belonging to the group

bleached with experimental gel

\section{AFM analysis of enamel microstructures}

Although, the overall appearance of the tooth enamel is very well observed in the SEM imaging, the fine microstructure details were highlighted using atomic force microscopy (AFM) at a scan area of $5 \mu \mathrm{m} \times 5 \mu \mathrm{m}$. The samples of untreated enamel have a well-maintained surface (Figure 5a), where we notice the special compactness of the hydroxyapatite crystallites (HAP) structures. The only signs that the tooth was used for chewing are some low depression (darker areas), which is due to the natural wear of the tooth. 

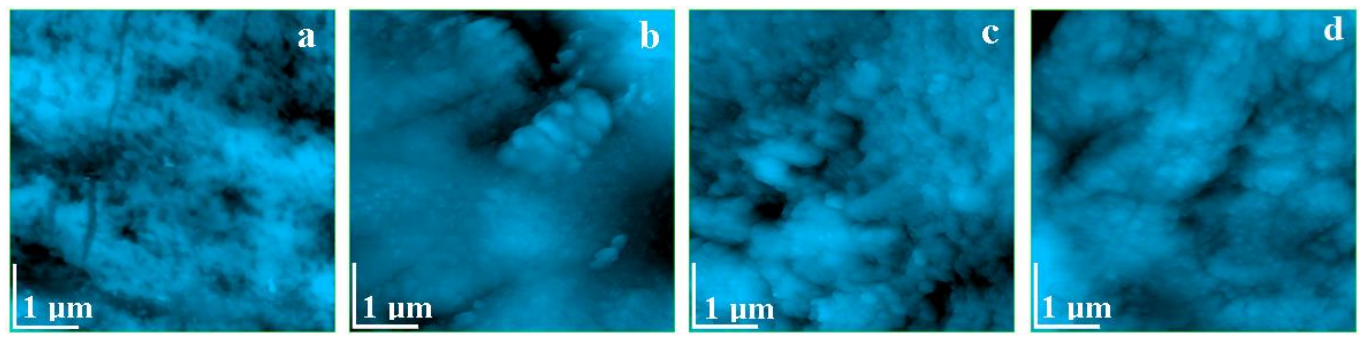

Figure. 5. AFM topographic images of the enamel microstructure: a) untreated, b) stained, c) bleached with Opalescence gel, and d) bleached with experimental gel (scanned area: $5 \mu \mathrm{m} \times 5 \mu \mathrm{m}$ )

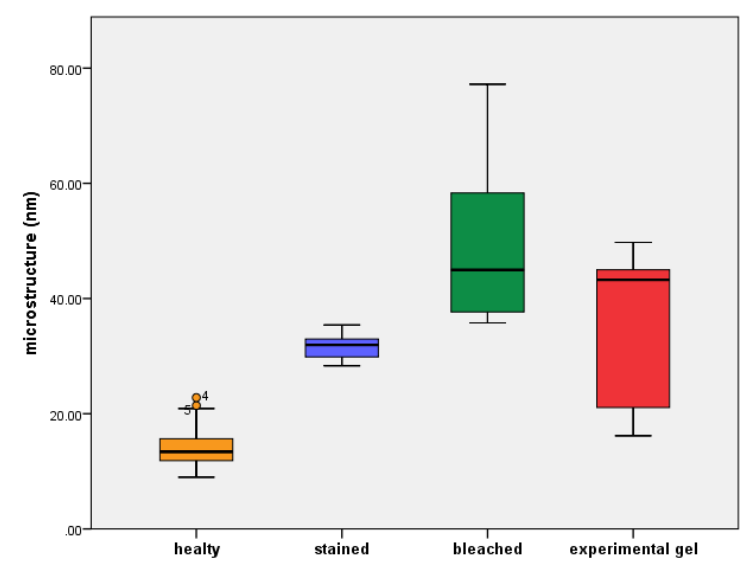

Figure 6. Mean roughness values of enamel microstructure

At the nanostructure AFM analysis, the samples of untreated tooth enamel, respectively the control group, we can observe better the hydroxyapatite crystallites very well bonded to each other (Figure $6 a)$. The reference values of the roughness (Ra) at the nanostructure level are shown in Figure 7.

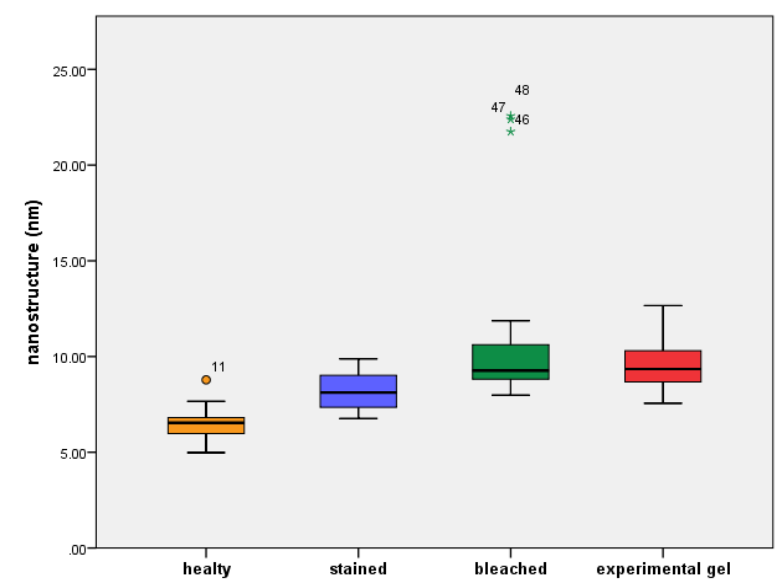

Figure 7. Mean

roughness values of

enamel nanostructure

In AFM analysis of the dental samples after they have been subjected to the staining process, a surface with microstructural differences associated with deposits is highlighted. As shown in Figure $5 \mathrm{~b}$, these are in the form of ovoid agglomerates of the chromophore substance physically fixed to the enamel surface. At the AFM analysis of the enamel nanostructure, the enamel in the experimental group treated with coffee solution presents altered hydroxyapatite crystallites with elongated ovoid form, aspect illustrated in Figure 8b. The high degree of alteration of the morphology of the HAP crystallites also indicates acid erosion produced by the staining substance, followed by its massive deposition on the enamel surface, thus increasing the enamel surface roughness (Figure 7).

The AFM analysis of the bleached group with Opalescence, GO, shows a surface that is observed following the blurring induced by the stains that have affected the enamel, but which is markedly 
improved (Figure 5c). We appreciate that the Opalescence whitening gel provides the enamel healthy surface appearance, eliminating the chromophore conglomerates, although its roughness remains high (Figure 8). At the nanostructure level, the reinvigorated appearance of the enamel is also highlighted, and the HAP crystallites are very well bonded together, with a multilayered spheroid appearance. This fact explains the increased roughness to that of the healthy enamel (Figure 7).

In the AFM analysis of the enamel of the study group bleached with the experimental gel, we have detected a very good removal of the differences induced by coffee staining of the tooth, which correlates with an improved aesthetic aspect of the samples (Figure 5c). We can say that bleaching with the experimental gel leads to the best whitening result from the point of view of restoring the healthy enamel stage (Figure 5d). The enamel surfaces of the group treated with experimental gel show after treatment, at the microscopic aspect analysis, morphology identical to that of the untreated enamel, also having an average roughness value for some samples very close to that of the untreated enamel (Figure 6). It is also observed the successful removal of stains and impurities, as well as the preservation of the compact structure of HAP crystallites. This aspect is also confirmed by AFM analysis of the enamel nanostructure, where the compact and smooth structure of the enamel is observed after treatment. The mean diameter of HAP crystallites is close to that of healthy enamel and, also the roughness measured at this level is close to that of the untreated group (Figure 7, Figure 8d). This is proof that the treatment was able to completely remove the stains, but also led to the repair of chemical erosion traces.
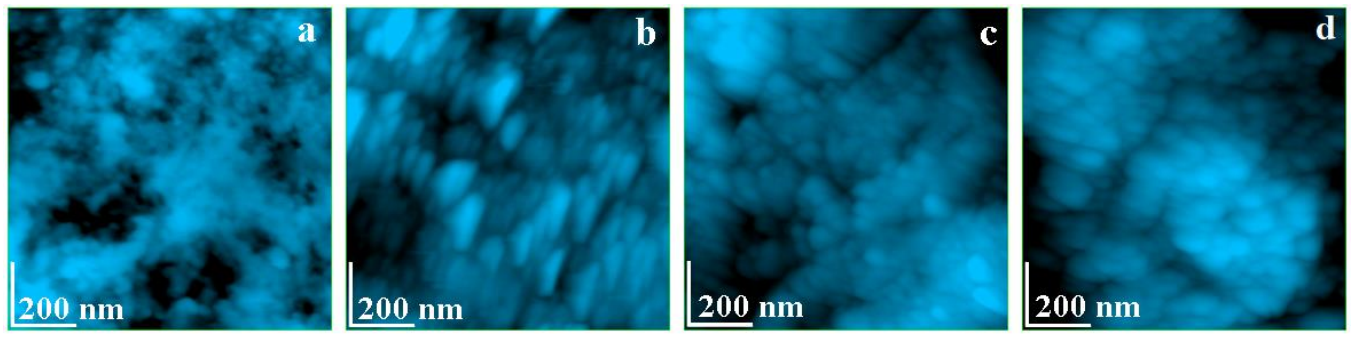

Figure. 8. AFM topographic images of the enamel nanostructure: a) healthy

b) stained with coffee, c) bleached with Opalescence gel, and d) experimental gel bleach and (scanned area: $1 \mu \mathrm{m} \times 1 \mu \mathrm{m}$ )

Numerous studies have shown that the effects of bleaching agents on tooth enamel can range from insignificant to major changes in its structure and morphology depending on the whitening protocol used [16-18]. In the idea of these studies it was shown that the higher the concentration of carbamide peroxide, the more, the surface micro-hardness was altered [19]. These changes are correlated with the oxidative action of hydrogen peroxide on the organic phase of hard dental tissues [21]. This disturbance of the structure of the organic matrix of the tooth enamel consists in the removal of inorganic elements from the matrix, resulting in erosion zones interspersed with healthy areas, giving the enamel a macroscopic rough appearance $[18,21]$. Also, as a result of this increase of the porosity of the enamel after bleaching, the penetration power of hydrogen peroxide also increases towards the dental pulp [21-23].

Other research has suggested that increasing enamel roughness after whitening with carbamide peroxide gels may favor the adhesion of Streptococcus mutants to the dental surface [24]. Also, in this direction, Heshmat et al concluded that the acid can diffuse into the tooth and dissolve carbonated hydroxyapatite, resulting in a de-mineralized porous enamel of similar appearance to that of carious lesions [25].

It is also known that saliva is capable of re-mineralizing enamel hydroxyapatite crystals due to its ability to supply calcium and phosphate ions. At a physiological level of $p \mathrm{H}$, saliva is supersaturated in calcium and phosphate ions [26]. However, on the other hand, it has been shown that the precipitation of phosphate and calcium ions in saliva does not normally occur, due to the presence of salivary 
proteins, especially statherine and proline-rich phosphoproteins [27, 28].

Although some studies have concluded that the roughness of the bleached enamel can be improved by refilling with ions contained in saliva, however, prolonged use of whitening gels can disrupt the demineralization balance, caused by the bleaching and re-mineralizing agent based on the saliva buffering capacity [29]. In addition, an improvement of the re-mineralization of bleached enamel has been reported by the application of nano-hydroxyapatite products, which act as micro porosity closing agents, resulting from the loss of mineral ions during tooth whitening [30].

In this context, some studies have proposed the use of substances, which fill the microporosity produced by bleaching with different results; Attin et al demonstrated the positive effect of topical application of 5\% sodium fluoride [31]. Other research has concluded that local fluoride applications, on the contrary, do not improve the surface alterations of the enamel [32].

Based on these changes in the enamel surface during the bleaching treatment, the researchers proposed the problem of developing and studying some preparations, which would stimulate the remineralization of the affected enamel or fill the gaps created in its organic matrix. Thus, Jose et al concluded that before the application of re-mineralization agents, the application of tea-based preparations may be an accept option to re-mineralize the de-mineralized hard dental tissues [33]. Yu et al concluded in a study that, in addition to fluorine, the organic components of tea also have the property of increasing the acid resistance of tooth enamel. It also suggests that organic components seem to play a major role in their actions, rather than fluoride [34].

Mukka et al indicated the use of pomegranate peel extracts, grape seeds and pine bark as antioxidants immediately after the bleaching procedure [35].Another study showed that toothpaste containing $15 \%$ green tea extract favored re-mineralization of white enamel, showing an increased value of micro roughness [36]. De Moraes et al concluded that the use of green tea extract applied to dentin can be an effective means of protection in reducing the erosion process of dentin by its protective effect on the roughness and wear of dentin following erosion [37].

\section{Conclusions}

After the bleaching treatment was completed, both experimental groups showed increased microstructural roughness compared to the untreated control group. Following the bleaching with Opalescence gel, the enamel surface shows a modified architecture compared to the one of the healthy, untreated enamel, and the roughness at both microstructural and nanostructure level has higher values than the control group.The experimental gel whitening group based on green tea extract and caramide peroxide showed microstructural levels with respect to the control group, but at the nanostructure level it had similar values to the control group.

\section{References}

1.MAHMOUD, S.H, ELEMBAY, A.E, ZAHER, A.R, GRAWISH, M.E, ELSABAA, H.M, ELNEGOLY, S.A, SOBH, M.A., Effect of $16 \%$ carbamide peroxide bleaching gel on enamel and dentin surface micromorphology and roughness of uremic patients: an atomic force microscopic study. Eur.J.Dent, 4(2), 2010, 175.

2.SULIEMAN, M., An overview of bleaching techniques: history, chemistry, safety and legal aspects (part 1). SADJ, 61(7), 2006, 304.

3.AKAL, N., OVER, H., OLMEZ, A., BODUR, H., Effects of carbamide peroxide containing bleaching agents on the morphology and subsurface hardness of enamel, J.Clin. Pediatr. Dent., 25(4), 2002, 293-296.

4.EIMAR, H., SICILIANO, R., ABDALLAH, M.N.,NADER, S.A., AMIN, W.M., MARTINEZ, P.P., CELEMIN, A., CERRUTI, M., TAMIMI, F., Hydrogen peroxide whitens teeth by oxidizing the organic structure J. Dent., 40, 2012, 25-33. 
5.SILVA, B.G., GOUVEIA, T.H., DA SILVA, M.D., AMBROSANO, G.M., AGUIAR, F.H., LIMA, D.A., Evaluation of home bleaching gel modified by different thickeners on the physical properties of enamel: An in situ study Eur. J. Dent., 12 (4), 2018, 523.

6.DE OLIVEIRA, R.P., BAIA, J.C., RIBEIRO, M.E., E SOUZA, M.H., Influence of Time Intervals between Bleaching Procedures on Enamel Micro hardness and Surface Roughness, Open. Dent. J, 12, $2018,555$.

7.SASAKI, R.T., FLORIO, F.M., BASTING, R.T., Effect of $10 \%$ sodium ascorbate and $10 \% \alpha-$ tocopherol in different formulations on the shear bond strength of enamel and dentin submitted to a home-use bleaching treatment. Oper. Dent., 34 (6) 2009, 746-752.

8.DE ABREU, D.R., SASAKI, R.T., AMARAL, F.L., FLORIO, F.M., BASTING, R.T., Effect of Home-Use and In-Office Bleaching Agents Containing Hydrogen Peroxide Associated with Amorphous Calcium Phosphate on Enamel Microhardness and Surface Roughness. J. Esthet. Restor. Dent., 23 (3), 2011, 158-168.

9.RAJAB, S., AL MARSAFY, S., AL SOUFY, M., Effect of Chinese Green Tea on Enamel Surface Characteristics in an in-vitro Erosion Model. ADJG, 5 (3), 2018, 257-266.

10.PASSOS, V.F., MELO, M.A., LIMA, J.P., MARÇAL, F.F., COSTA, C.A., RODRIGUES, L.K., SANTIAGO, S.L., Active compounds and derivatives of camellia sinensis responding to erosive attacks on dentin. Braz. Oral Res., 32, 2018.

11.TAYLOR, P.W., HAMILTON-MILLER, J.M., STAPLETON, P.D., Antimicrobial properties of green tea catechins. Food Sci. Technol. Bull., 2 (7), 2005, 71-81.

12.FERAZZANO, G.F., AMATO, I., INGENITO, A., DE NATALE, A., POLLIO, A., Anti-cariogenic effects of polyphenols from plant stimulant beverages (cocoa, coffee, tea). Fitoterapia, 80 (5), 2009, 255-262.

13.AZIMI, S., MANSOURI, Z., BAKHTIARI, S., TENNANT, M., KRUGER, E., RAJABIBAZL, M., et al. Does green tea consumption improve the salivary antioxidant status of smokers? Arch Oral Biol., 78, 2017, 1-5.

14.PELUSO, I., SERAFINI, M., Antioxidants from black and green tea: From dietary modulation of oxidative stress to pharmacological mechanisms. Br. J Pharmacol., 174 (11), 2017, 1195-1208.

15.SERAFINI, M., DEL RIO, D., YAO, D.N., BETUZZI, S., PELUSO, I., Herbal Medicine: Biomolecular and Clinical Aspects, ed. FF Benzie and S. Wachtel-Galor, CRC Press, Boca RatonUSA. 2011, 473.

16.LAMBERT, J.D., ELIAS, R.J., The antioxidant and pro-oxidant activities of green tea polyphenols: a role in cancer prevention. Arch. Biochem. Bioph, 501(1), 2010, 65-72.

17.SPALDING, M., TAVEIRA, L.A., DE ASSIS, G.F., Scanning electron microscopy study of dental enamel surface exposed to $35 \%$ hydrogen peroxide: alone, with saliva, and with $10 \%$ carbamide peroxide. J EsthetRestor Dent., 15 (3), 2003, 154-165.

18.PINTO, C.F., LEME, A.F., CAVALLI, V., GIANINI, M., Effect of $10 \%$ carbamide peroxide bleaching on sound and artificial enamel carious lesions. Braz. Dent J.,20 (1), 2009, 48-53.

19.USHIGOME, T., TAKEMOTO, S., HATTORI, M., YOSHINARI, M., KAWADA, E., ODA, Y., Influence of peroxide treatment on bovine enamel surface - Cross-sectional analysis - Dent Mat J., 28 (3), 2009, 315-323.

20.SOARES, D.G., RIBEIRO, A.P., SACONO, N.T., LOGUERCIO, A.D., HEBLING, J., COSTA, C.A., Mineral loss and morphological changes in dental enamel induced by a $16 \%$ carbamide peroxide bleaching gel. Braz Dental J., 24 (5), 2013, 517-521.

21.EIMAR, H., SICILIANO, R., ABDALLAH, M.N., NADER, S.A., AMIN, W.M., MARTINEZ, P.P., CELEMIN, A., CERRUTI, M., TAMIMI, F., Hydrogen peroxide whitens teeth by oxidizing the organic structure. J Dent., 40, 2012, 25-33.

22.DUDEA, D., FLOREA, A., MIHU, C., CAMPEANU, R., NICOLA, C., BENGA, G.H., The use of scanning electron microscopy in evaluating the effect of a bleaching agent on the enamel surface. Rom J MorpholEmbryol., 50 (3), 2009, 435-440. 
23.RODRIGUES, L.M., VANSAN, L.P., PECORA, J.D., MARCHESAN, M.A., Permeability of different groups of maxillary teeth after $38 \%$ hydrogen peroxide internal bleaching. Braz Dental J., 20 (4) 2009, 303-306.

24.NAM, S.H., OK, S.M., KIM, G.C., Tooth bleaching with low-temperature plasma lowers surface roughness and Streptococcus mutans adhesion. Inter Endo J., 51 (4), 2018, 479-488.

25.HESHMAT, H., GANJKAR, M.H., JABERI, S., FARD, M.J., The effect of remin pro and MI paste plus on bleached enamel surface roughness. J Dent (Tehran), 11 (2), 2014, 131.

26.LARSEN, M.J., PEARCE, E.I., Saturation of human saliva with respect to calcium salts. Arch Oral Biol, 48 (4), 2003, 317-322.

27.SCHLESINGER, D.H., HAY, D.I., Complete covalent structure of statherin, a tyrosine-rich acidic peptide which inhibits calcium phosphate precipitation from human parotid saliva. J Biol Chem, 252 (5), 1977, 1689-1695.

28.HAY, D.I., Salivary factors in caries models. ADR,9 (3), 1995, 239-243.

29.CVIKL, B., LUSSI, A., MORITZ, A., FLURY, S., Enamel surface changes after exposure to bleaching gels containing carbamide peroxide or hydrogen peroxide. Oper Dent, 41 (1), 2016, 39-47.

30.KHOROUSHI, M., SHIRBAN, F., DOUSTFATEME, S., KAVEH, S., Effect of three nanobiomaterials on the surface roughness of bleached enamel. ContempClin Dent, 6 (4), 2015, 466.

31.ATTIN, T., SCHMIDLIN, P.R., WEGEHAUPT, F., WIEGAND, A., Influence of study design on the impact of bleaching agents on dental enamel micro hardness: a review. Dent Mat., 25 (2), 2009, 143-157.

32.DIONYSOPOULOS, D., KOLINIOTOU-KOUMPIA, E., TOLIDIS, K., GERASIMOU, P., Effect of fluoride treatments on bleached enamel micro hardness and surface morphology. Oral Health Prev Dent., 15 (2), 2017, 169-175.

33.JOSE, P., SANJEEV, K., SEKAR, M., Effect of green and white tea pretreatment on remineralization of demineralized dentin by CPP-ACFP-an in vitro micro hardness analysis. JCDR, 10 (4), 2016, ZC85.

34.YU, H., OHO, T., XU, L.X., Effects of several tea components on acid resistance of human tooth enamel. J Dent., 23 (2), 1995, 101-105.

35.MUKKA, P.K., KOMINENI, N.K., POLA, S., SOUJANYA, E., KARNE, A.R., NENAVATH, B., SHIVA, S., VUPPUNTHULA, P., An in-vitro comparative study of shear bond strength of composite resin to bleached enamel using three herbal antioxidants. JCDR, 10(10), 2016, ZC89.

36.FEBRIAN, K., TRIAMININGSIH, S., INDRANI, D.J., In-vitro study investigating influence of toothpaste containing green tea extract on the micro hardness of demineralized human enamel. J Phys Conf Ser, 884 (1), 2017, 12.

37.DE MORAES, M.D., CARNEIRO, J.R., PASSOS, V.F., SANTIAGO, S.L., Effect of green tea as a protective measure against dental erosion in coronary dentine. Braz. Oral Res., 30 (1), 2016.

Manuscript received: 24.03 .2020 